\title{
Bladder Outlet Obstruction in Painful Bladder Syndrome/Interstitial Cystitis
}

\author{
Anne P. Cameron ${ }^{1 *}$ and Jerzy B. Gajewski ${ }^{2}$ \\ ${ }^{1}$ Department of Urology, University of Michigan, Ann Arbor, Michigan \\ ${ }^{2}$ Department of Urology, Dalhousie University, Halifax, Nova Scotia, Canada
}

\begin{abstract}
Aims: Obstructive symptoms such as slow stream, dribbling and straining are often reported by painful bladder syndrome and interstitial cystitis (PBS/IC) patients. Our hypothesis was that some patients with PBS/IC have an associated measurable bladder outlet obstruction (BOO) secondary to dysfunctional voiding and that those patients with more severe PBS/IC are more likely to have BOO. Methods: This is a retrospective chart review of female patients diagnosed with PBS/IC based on the NIDDK research definition. Charts were reviewed for clinical symptom severity, ulcer or non-ulcer PBS/IC on cystoscopy, and pressure-flow urodynamics (UDPF). Patients were excluded if they had a urinary infection at the time of urodynamics or did not meet study entry requirements. The cut-off values of $\leq 12 \mathrm{ml} / \mathrm{sec}$ and $\geq 25 \mathrm{~cm}$ of water was used to define BOO. Results: Of the 231 women: 38 had ulcer PBS/IC and 193 had non-ulcer PBS/IC. MCC was $269 \mathrm{ml}$ in non-ulcer PBS/IC and $200 \mathrm{ml}$ in ulcer PBS/IC $(P=0.006)$. One hundred eleven women $(48 \%)$ met criteria for obstruction. MCC was $298 \mathrm{ml}$ in the non-obstructed group and $214 \mathrm{ml}$ in the obstructed group $(P<0.0001)$. The maximum flow with non-ulcer PBS/IC was $11.0 \mathrm{ml} / \mathrm{sec}$ and in ulcer PBS/IC $8.9 \mathrm{ml} / \mathrm{sec}(P=0.04)$ Detrusor pressure at maximum flow was $33.3 \mathrm{~cm} \mathrm{H}_{2} \mathrm{O}$, in non-ulcer, and $37.4 \mathrm{~cm} \mathrm{H}_{2} \mathrm{O}$ in ulcer PBS/IC $(P=0.01)$. Conclusions: Forty-eight percent of our PBS/IC patients have BOO, and increasing severity of PBS/IC is associated with higher voiding pressure. Neurourol. Urodynam. 28:944-948, 2009. () 2009 Wiley-Liss, Inc.
\end{abstract}

Key words: female; urinary bladder neck obstruction; urodynamics

\section{INTRODUCTION}

Painful bladder syndrome (PBS) is defined by the International Continence Society as "the complaint of suprapubic pain related to bladder filling, accompanied by other symptoms such as increased day- and night-time frequency, in the absence of proven urinary infection or other obvious pathology" and the diagnosis of interstitial cystitis (IC) is reserved for those who have "typical cystoscopic and histologic features". ${ }^{1}$ It is a common entity with the prevalence of PBS symptoms reported as frequently as $0.83-2.71 \%$ in women. ${ }^{2}$

$\mathrm{PBS} / \mathrm{IC}$ is a chronic disease that is very difficult to treat. Life style modifications, oral medications, hydrodistension, intravesical treatment, sacral nerve modulation, and surgical treatment have all been attempted with varying degrees of success. ${ }^{3}$ In our experience, some women with PBS/IC also complain of symptoms of voiding dysfunction including bladder outlet obstruction (BOO). They have a sensation of incomplete emptying, slow stream, straining to void, and dribbling. There is little data in the literature on urodynamic pressure-flow (UDPF) studies in PBS/IC patients. Recently, several authors have published pressure-flow criteria to diagnose female BOO. ${ }^{4-10}$ In our patient population we have a significant number of PBS/IC patients who have undergone UDPF and with these criteria there existed an opportunity to assess our patient population with PBS/IC for possible obstruction. We hypothesized that some patients with PBS/IC had an associated measurable BOO and that those patients with the more severe ulcer variant of PBS/IC were more likely to have $\mathrm{BOO}$ and worse urinary symptoms.

\section{MATERIALS AND METHODS}

After institutional review board approval all of our PBS/IC patient population had their charts retrospectively reviewed.
Two hundred seventy-four patients who met the National Institute of Diabetes, Digestive and Kidney Disease (NIDDK) research definition of $\mathrm{IC}^{11}$ had completed pressure-flow urodynamic studies (UDPF), a urinary symptom score (Table I) and had a cystoscopy with hydrodistention from May 1996 to June 2004 were included (Appendix A). It was routine practice at that time to perform urodynamics and cystoscopic hydrodistention under general anesthetic on all women with suprapubic pain and lower urinary tract symptoms. Any woman with missing data (18 patients) or a urinary tract infection at the time of UDPF ( 5 patients) was excluded. Twenty patients were excluded because their urodynamic studies could not be interpreted since they could not void during the study. Patients were also excluded if they did not meet NIDDK research definition, except for the presence of detrusor instability, which we did not consider an exclusion criterion. ${ }^{12}$ Information collected included past medical history, gynecological or urologic surgery, history of stones or UTI, neurologic disease, parity, age, and incontinence.

The symptom score was collected verbally by the examiner and included questions regarding frequency, urgency, nocturia, and suprapubic pain. Scores were calculated based on our grading system (Table I).

A physical examination was also performed specifically noting the presence of suprapubic pain on palpation. All patients had a cystoscopic examination under general

\section{Conflict of interest: none.}

Dirk De Ridder led the review process.

${ }^{*}$ Correspondence to: Anne P. Cameron, MD, 1500 E Medical Center Drive, 3875

Taubman Center, Ann Arbor, MI 48109. E-mail: annepell@med.umich.edu

Received 28 November 2008; Accepted 18 February 2009

Published online 19 March 2009 in Wiley InterScience

(www.interscience.wiley.com)

DOI 10.1002/nau.20729 
TABLE I. Symptoms Score

\begin{tabular}{lcccc}
\hline Symptoms & $\mathbf{0}$ & $\mathbf{1}$ & $\mathbf{2}$ & $\mathbf{3}$ \\
\hline Frequency & $>\mathrm{q} 2 \mathrm{~h}$ & $\mathrm{q} 2 \mathrm{~h}$ & $\mathrm{q} 1-2 \mathrm{~h}$ & $<\mathrm{q} 1 \mathrm{~h}$ \\
Nocturia & $0-1$ & 2 & $3-4$ & 5 \\
Suprapubic pain & None & Mild & Moderate & Severe \\
Urgency & None & 1/week & 1/day & Always \\
\hline
\end{tabular}

anesthetic and had bladder hydrodistention performed at $80 \mathrm{~cm}$ water pressure for a minimum of $60 \mathrm{sec}$. The bladder was then drained and re-examined for glomerulations. These were present in all cases and PBS/IC was classified as either ulcer (classic) or non-ulcer (non-classic) based on cystoscopic appearance. $^{13}$

After non-invasive uroflowmetry UDPF study was done in a standardized fashion in a semi-sitting position with a double lumen \#7 F urodynamics catheter in the bladder and a rectal balloon catheter to measure abdominal pressure. Bladder filling was performed at $50 \mathrm{ml} / \mathrm{min}$ with room temperature, sterile normal saline as the filling solution. All patients had both cystometry and pressure-flow studies. Patients were asked to void when they were comfortably full and this volume was recorded as the maximum cystometric capacity (MCC). Electromyography was performed using patch electrodes on the perianal area to assess pelvic floor relaxation. A single filling and voiding study was performed with a leak point pressure performed before voiding in the sitting position. Urodynamic studies were each interpreted independently by both authors and discrepancies in interpretation discussed and a consensus obtained. The cut-off values of maximum flow rate $\left(\mathrm{O}_{\max }\right) \leq 12 \mathrm{ml} / \mathrm{sec}$ and detrusor pressure at maximum flow $\left(\mathrm{P}_{\text {det }} \mathrm{Q}_{\max }\right) \geq 25 \mathrm{~cm} \mathrm{H} \mathrm{H}_{2} \mathrm{O}$ were used to define $\mathrm{BOO}$ in these women. ${ }^{6}$ Urodynamic data collected included $\mathrm{O}_{\max }, \mathrm{P}_{\text {det }} \mathrm{O}_{\max }, \mathrm{MCC}$, voided volume, and post void residual (PVR).

Urinary tract symptom severity was compared between the ulcer and non-ulcer cystoscopic appearance of PBS/IC and between those with BOO on UDPF and those without. For group comparison unpaired $t$-test, Mann-Whitney test, and Chi-square analysis were used. $P$-values of less than 0.05 were considered statistically significant.

\section{RESULTS}

There were 231 women with a mean age of $52.4 \pm 13.7$ years who were included in the study. One hundred ninety-three (83.5\%) had non-ulcer IC/PBS and 38 (16.5\%) had the ulcer variant. These groups were not different with respect to age, past medical history or surgical history except for hysterectomy, which was more common in the non-ulcer group 10/ 38 versus 93/193 ( $P=0.02$; Table II). On the individual urinary symptom questions, these groups were not different with respect to reported urinary frequency, urgency, nocturia or suprapubic pain, and the symptoms score sum was also not different (Table III). MCC was $269 \mathrm{ml}$ in non-ulcer PBS/IC and $200 \mathrm{ml}$ in ulcer variant $(P=0.006)$. Detrusor pressure at maximum flow was not significantly different between these two groups, but maximum flow was $11.0 \mathrm{ml} / \mathrm{sec}$ in non-ulcer and $8.9 \mathrm{ml} / \mathrm{sec}$ in ulcer PBS/IC $(P=0.04)$. The occurrence of detrusor overactivity on UDPF studies was not different between these two groups nor was the finding of suprapubic pain on physical examination. Mean PVR was $77.4 \mathrm{ml}$ in

TABLE II. Demographics and Medical History

\begin{tabular}{|c|c|c|c|c|c|c|}
\hline & \multicolumn{2}{|c|}{ PBS/IC } & \multirow[b]{2}{*}{$P$-value } & \multirow[b]{2}{*}{$\begin{array}{l}\text { Non-obstructed } \\
\quad(n=121)\end{array}$} & \multirow[b]{2}{*}{$\begin{array}{l}\text { Obstructed } \\
(n=111)\end{array}$} & \multirow[b]{2}{*}{$P$-Value } \\
\hline & $\begin{array}{l}\text { Non-classic } \\
(n=193)\end{array}$ & $\begin{array}{l}\text { Classic } \\
(n=38)\end{array}$ & & & & \\
\hline Age & $53.1 \pm 13.9$ & $49.8 \pm 13.1$ & 0.2 & $53.1 \pm 13.3$ & $51.6 \pm 14.1$ & 0.4 \\
\hline \multicolumn{7}{|l|}{ Medical history } \\
\hline IHD & 8 & 0 & 0.4 & 4 & 4 & 0.7 \\
\hline High cholesterol & 19 & 1 & 0.2 & 13 & 7 & 0.2 \\
\hline Thyroid disease & 24 & 1 & 0.09 & 14 & 11 & 0.8 \\
\hline Psychiatric disorder & 17 & 1 & 0.3 & 9 & 9 & 1.0 \\
\hline Arthritis & 34 & 3 & 0.2 & 16 & 21 & 0.2 \\
\hline Hypertension & 42 & 6 & 0.5 & 22 & 25 & 0.5 \\
\hline Asthma & 28 & 2 & 0.2 & 11 & 19 & 0.08 \\
\hline Bronchitis & 19 & 3 & 1.0 & 8 & 14 & 0.2 \\
\hline Stroke & 2 & 2 & 0.1 & 2 & 2 & 1.0 \\
\hline Diabetes & 15 & 0 & 0.1 & 6 & 9 & 0.4 \\
\hline Diverticulitis & 6 & 0 & 0.6 & 3 & 3 & 1.0 \\
\hline Endometriosis & 3 & 1 & 0.5 & 1 & 3 & 0.4 \\
\hline Stone disease & 3 & 1 & 0.5 & 2 & 2 & 1.0 \\
\hline UTIs & 2 & 2 & 0.1 & 2 & 2 & 1.0 \\
\hline \multicolumn{7}{|l|}{ Surgical history } \\
\hline Hysterectomy & 93 & 10 & 0.02 & 58 & 46 & 0.4 \\
\hline $\begin{array}{l}\text { Oophrectomy } \\
\text { alone }\end{array}$ & 9 & 1 & 0.5 & 3 & 7 & 0.2 \\
\hline Tubal ligation & 29 & 4 & 0.6 & 18 & 15 & 0.9 \\
\hline Anterior repair & 7 & 1 & 1.0 & 4 & 4 & 1.0 \\
\hline Bladder suspension & 40 & 4 & 0.2 & 22 & 22 & 0.9 \\
\hline \multicolumn{7}{|l|}{ Pregnancy } \\
\hline G & $2.8 \pm 1.9$ & $2.7 \pm 1.4$ & 0.8 & $2.9 \pm 1.8$ & $2.7 \pm 1.8$ & 0.7 \\
\hline $\mathrm{P}$ & $2.6 \pm 1.7$ & $2.7 \pm 1.3$ & 0.8 & $2.6 \pm 1.7$ & $2.6 \pm 1.7$ & 0.9 \\
\hline
\end{tabular}

Chi square analysis performed on all results.

$\mathrm{IH}$, dischemic heart disease; UTIs, urinary tract infections; G, gravida; P, para. 
TABLE III. Mean Urinary Symptom Scores

\begin{tabular}{lcccc}
\hline Group & Frequency score & Urgency score & Nocturia score & SPP score \\
\hline Non-ulcer PBS/IC & 1.8 & 1.8 & 1.3 & 1.3 \\
Ulcer PBSIIC & 1.9 & 1.7 & 1.3 & 1.3 \\
A/on-obstructed & $1.7^{\mathrm{a}}$ & 1.7 & 1.2 & 1.0 \\
Obstructed & $1.9^{\mathrm{a}}$ & 1.9 & 1.4 & 5.3 \\
\hline
\end{tabular}

Mann-Whitney test performed on all results.

SPP, suprapubic pain.

$P<0.05$.

non-ulcer and $56.2 \mathrm{ml}$ in ulcer disease, but this difference was not significant (Table IV).

Of the 231 women, 111 (48.1\%) were found to have urodynamic obstruction based on the cut-off values of $\mathrm{O}_{\max }$ $\leq 12 \mathrm{ml} / \mathrm{sec}$ and $\mathrm{P}_{\text {det }} \mathrm{O}_{\max } \geq 25 \mathrm{~cm} \mathrm{H}_{2} \mathrm{O} .{ }^{6} 46.6 \%$ of these women had non-ulcer PBS/IC and 55.2\% had the ulcer variant, but the difference between these two groups did not reach statistical significance $(P=0.7)$ (Fig. 1).

When comparing those with obstruction and those without, there was no statistical difference in age, past medical or surgical history (Table II). Individual urinary symptom scores were not significantly different between the groups except for urinary frequency, which was worse in the obstructed group and the score sum was significantly higher in the obstructed group (Table III). As expected, urodynamic parameters were very different in the two groups. Mean MCC was $214 \mathrm{ml}$ in the obstructed group and $298 \mathrm{ml}$ in the non-obstructed women $(P<0.0001)$. Also PVR was much higher in the obstructed group at $91.0 \mathrm{ml}$ than $58.2 \mathrm{ml}$ in the non-obstructed group $(P=0.006)$ (Table IV).

EMG data were unfortunately not sufficient for statistical analysis.

\section{DISCUSSION}

In this analysis $48.1 \%$ of women with an NIDDK research definition of IC had evidence of obstruction on pressure-flow urodynamics. This obstruction, we believe, is due to dysfunctional voiding and not stricture disease or other anatomical obstruction since none of these women had obstruction seen on cystoscopy and urodynamic catheterization was not difficult in any case. Also, there was no statistical difference in the number of anti-incontinence procedures in the obstructed group compared to the non-obstructed group (Table II). The women with ulcer PBS/IC had smaller MCC and slower maximum flows compared to those with the non- ulcer variety. The finding of more urodynamic obstruction in this ulcer PBS/IC group is not surprising since they have the more severe variant of the disease, which may cause the pelvic floor to be less able to relax during voiding because of more severe pain. This coincides with our initial hypothesis that the more severe ulcer variant of PBS/IC would have a greater likelihood of BOO, unfortunately the number of women who met the obstruction criteria that we selected was not different between the groups.

We had postulated that painful voiding was at the root of the problem with pain causing reflexive poor pelvic floor relaxation. The concept of bladder pain causing outlet obstruction is not new. Webster studied 152 women with recurrent cystitis with pressure-flow videourodynamic studies and found that a third were actually obstructed, with the obstruction seen at the area of external sphincter. He proposed that the external sphincter was in spasm in response to a nearby inflammation and that these spasms should normally abates, but with chronic inflammation a vicious cycle is set up with persistent outflow obstruction. ${ }^{14}$ In a different study evaluating the pelvic floor of 70 women with IC, 87\% were found to have levator pain consistent with pelvic floor dysfunction. ${ }^{15}$ Other authors agree with the hypothesis that external sphincter spasticity syndrome ${ }^{16-18}$ or failure of pelvic floor relaxation ${ }^{17,19}$ can arise from inflammatory conditions or pain in the lower urinary tract.

Bladder symptoms that define IC/PBS and symptoms of BOO have been shown to overlap and exist together more frequently than would be expected by chance in the Boston Area Community Health Survey. This survey queried over 3,000 racially diverse community dwelling women and found that $0.5 \%$ of the women reported pure symptoms of IC/PBS, $11.4 \%$ reported pure obstructive type symptoms, and $1.1 \%$ reported both, making the overlap of symptoms more than twice as prevalent as pure IC/PBS symptoms. ${ }^{20}$ A questionnaire sent to a sample of patients from Kaiser Permanente

TABLE IV. Urodynamic Results

\begin{tabular}{|c|c|c|c|c|c|c|}
\hline & \multicolumn{2}{|c|}{ PBS/IC } & \multirow[b]{2}{*}{$P$-value } & \multirow[b]{2}{*}{ Non-obstructed } & \multirow[b]{2}{*}{ Obstructed } & \multirow[b]{2}{*}{$P$-value } \\
\hline & Non-ulcer & Ulcer & & & & \\
\hline Free flow maximum flow rate $(\mathrm{ml} / \mathrm{sec})$ & 14.1 & 12.2 & 0.2 & 15.8 & 10.6 & 0.0006 \\
\hline Volume at first sensation (ml) & 126.4 & 129.3 & 0.4 & 147.4 & 104.6 & 0.0007 \\
\hline $\operatorname{MCC}(\mathrm{ml})$ & 269 & 200 & 0.006 & 298 & 214 & $<0.0001$ \\
\hline $\mathrm{P}_{\text {det }}$ at maximum flow $\left(\mathrm{cm} \mathrm{H}_{2} \mathrm{O}\right)$ & 33.3 & 37.4 & 0.1 & 23.1 & 45.8 & $<0.0001$ \\
\hline Detrusor overactivity present & $18.6 \%$ & $13.2 \%$ & 0.2 & $20.0 \%$ & $15.5 \%$ & 0.4 \\
\hline $\mathrm{O}_{\max }(\mathrm{ml} / \mathrm{sec})$ & 11.0 & 8.9 & 0.04 & 14.4 & 6.5 & $<0.0001$ \\
\hline Residual Urine (ml) & 77.4 & 56.2 & 0.2 & 58.2 & 91.0 & 0.006 \\
\hline Suprapubic pain on exam & $70.6 \%$ & $68.4 \%$ & 0.3 & $69.9 \%$ & $71.4 \%$ & 0.9 \\
\hline BOO according to criteria & $46.6 \%$ & $55.2 \%$ & 0.7 & - & - & - \\
\hline Ulcer PBS/IC & - & - & - & $18.9 \%$ & $14.2 \%$ & 0.4 \\
\hline
\end{tabular}

PBS, painful bladder syndrome; IC, interstitial cystitis; MCC, maximum cystometric capacity; $\mathrm{P}_{\text {det }}$, detrusor pressure; $\mathrm{O}_{\text {max }}$ maximum flow; BOO, bladder outlet obstruction. 


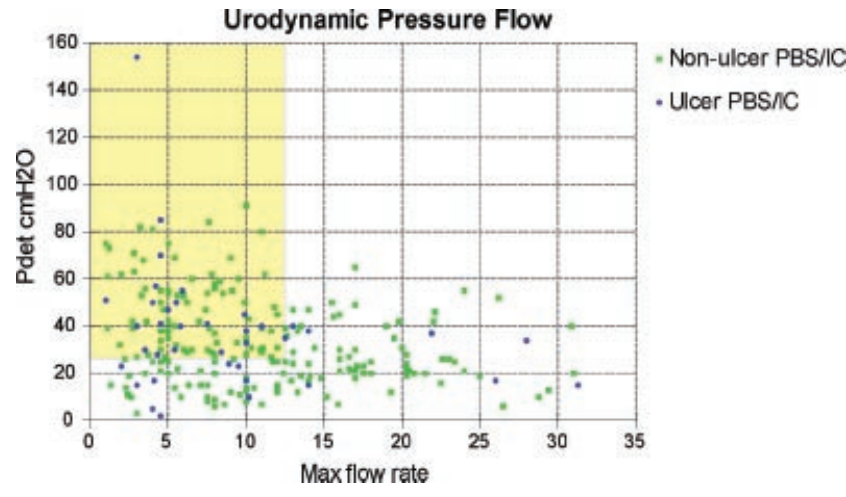

Fig. 1. Scatter plot of urodynamic detrusor pressure at maximum flow $\left(\mathrm{P}_{\text {det }} \mathrm{O}_{\text {max }}\right)$ and maximum flow rates $\left(\mathrm{Q}_{\max }\right)$ of entire cohort. The values corresponding with obstruction are in the yellow box.

found similar overlap in symptoms of bladder pain, voiding symptoms, and storage symptoms. ${ }^{21}$

BOO in women has, until recently, had no objective criteria on uroflow or urodynamic studies. Several recent publications have developed pressure-flow nomograms using data from patients with anatomical obstruction, however there continues to be no universally accepted definition of BOO in women. $^{22}$ Our cut-off of $\mathrm{O}_{\max } \leq 12 \mathrm{ml} / \mathrm{sec}$ and $\mathrm{P}_{\text {det }} \mathrm{Q}_{\max }$ $\geq 25 \mathrm{~cm} \mathrm{H}_{2} \mathrm{O}$ was based on the work of Defreitas and Zimmern who studied UDPF in 169 women with clinically proven anatomical obstruction compared to 20 female volunteer without urologic symptoms or previous urologic surgery. ${ }^{6}$ We deemed this to be the most accurate criteria since they employed true asymptomatic controls to create their cut points. Unfortunately, none of their cohort had functional obstruction like those in our study, but all had a physical obstruction, possibly reducing the generalizability of these values to our population. These criteria were an extension of this group's previous work at developing a cut-point for BOO in women. Their first proposed cut-off was a $\mathrm{O}_{\max } 15 \mathrm{ml} / \mathrm{sec}$ or less and $\mathrm{P}_{\text {det }} \mathrm{O}_{\max }>20 \mathrm{~cm} \mathrm{H} \mathrm{H}_{2} \mathrm{O}$, but compared UDPF in women with obstruction to those with stress urinary incontinence as controls. ${ }^{4}$ Their second definition of obstruction was ${ }_{\max }$ of

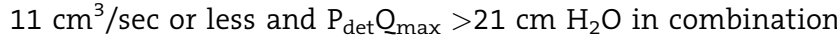
with a clinical history and symptoms suggesting obstruction, but these were again using women with stress incontinence as the controls. ${ }^{23}$

Other authors have proposed various cut-points, ${ }^{5,8-10,24}$ but in a comparison of five different diagnostic criteria to one another, ${ }^{22}$ the cut-point chosen for our analysis was felt to actually underestimate obstruction compared to fluoroscopic urodynamics, and other criteria ${ }^{4}$ to greatly overestimated it. Unfortunately, larger multi-center trials to validate these values for an accepted definition of BOO in women are still pending.

There are many limitations to our analysis. The NIDDK research definition used to diagnose PBS/IC in this study are very rigid and are designed for use in research, not clinical practice. Many people with IC/PBS do not meet these exhaustive criteria, but would be routinely diagnosed in a clinical setting so there are many patients unnecessarily excluded from this study. ${ }^{11}$

The urinary symptoms score, routinely employed in our center at the time of the study, were essentially no different between the ulcer and non-ulcer group, but was significantly higher in the obstructed group compared to the nonobstructed group. This was an unexpected finding since we had hypothesized that the ulcer variant of the disease would be more symptomatic due to their more severe disease. However, this was not a validated questionnaire and their results should be interpreted as such.

There were many difficulties with the urodynamic evaluation of these women with PBS/IC. Twenty women were simply unable to void during the study and were therefore excluded. Ambulatory uroflows were done on all of these patients prior to the urodynamics. However, only 122 of the women had a large enough voided volumes $\left(\geq 150 \mathrm{~cm}^{3}\right)$ to be interpreted; therefore we did not use these results in establishing the diagnosis of BOO. Many would argue that free uroflows give a more accurate assessment of obstruction than uroflowmetry with a catheter during urodynamics. ${ }^{8,25}$

We do not have any fluoroscopic information on the physical appearance of the bladder neck or outlet in these studies to confirm the diagnosis of obstructive voiding. This information would have been helpful in determining the exact etiology of the obstruction. , $^{94}$

The number of women who met the obstruction criteria that we selected pre-study was not different between the ulcer and non-ulcer IC/PBS groups. We do not know, however, if this would be different if we had chosen a different urodynamics criteria for obstruction.

We had hoped that the EMG results would help to answer the question of the etiology of the $\mathrm{BOO}$ being either a detrusor contractility dysfunction, a learned behavior with poor pelvic floor relaxation, or an actual outlet obstruction. We had postulated that painful voiding was at the root of the problem with pain causing a reflexive poor pelvic floor relaxation. Unfortunately, the EMG data were not sufficient to make any conclusions. However, we did see a higher bladder pressures generated with the more severe ulcer IC/PBS with voiding leading us to believe that these more severe cases of IC/PBS have worse obstruction, not detrusor dysfunction.

Since PBS/IC is such a difficult disease to successfully treat, most clinicians would welcome any further insight into better management options. Given the likely functional cause of the BOO seen in these women with PBS/IC supported by other authors who have found significant pelvic floor dysfunction in this group ${ }^{15}$ we suggest pelvic floor physical therapy, biofeedback, muscle relaxants or alpha blockers as possible non-invasive treatment regimens. These therapies have been shown to be effective in functional external sphincter nonrelaxation. ${ }^{16,26,27}$ Another more invasive treatment modality that is effective for female functional BOO and PBS/IC is sacral neuromodulation ${ }^{26}$ and should be considered in refractory cases.

In agreement with the International Consultation on IC in Japan and the $\mathrm{NIDDK}^{12}$ we do not recommend routine urodynamic investigation of women with PBS/IC since most are treated clinically with little added information from urodynamics. This cohort had UDF studies done prior to the current recommendations and is a representative sample of patients with PBS/IC in a tertiary care practice.

\section{CONCLUSION}

This study had confirmed our suspicions that some IC/PBS patients do indeed have an element of obstructive voiding on urodynamics. The etiology of the obstructed has still not been elucidated, but is likely due to pelvic floor spasm secondary to painful voiding. Future treatment strategies in women who do have evidence of this obstruction could include alpha-1 
adrenergic blockers or biofeedback exercises to try to relax the pelvic floor.

\section{APPENDIX A}

\section{Exclusion Criteria}

Urinary infection at time of urodynamics.

Patient unable to void during pressure-flow study.

Missing data.

\section{Inclusion Criteria}

Meet the NIDDK Diagnostic Criteria for $\mathrm{IC}^{1}:^{11}$

To be diagnosed with IC, patients must have either glomerulations on cystoscopic examination or classic Hunner's ulcer, and they must have either pain associated with the bladder or urinary urgency. An examination for glomerulations should be undertaken after distension of the bladder with the patient under general anesthesia to $80-100 \mathrm{~cm}$ water pressure for 1-2 min. The bladder may be distended up to two times before evaluation. The glomerulations must be diffuse, present in at least 3 quadrants of the bladder, and there must be at least 10 glomerulations per quadrant. The glomerulations must not be along the path of the cystoscope (to eliminate artefact from contact instrumentation). The presence of any of the following criteria excludes the diagnosis of IC:

(1) Bladder capacity greater than $350 \mathrm{~cm}^{3}$ on awake cystometry using either a gas or liquid filling medium.

(2) Absence of an intense urge to void with the bladder filled to $100 \mathrm{~cm}^{3}$ gas or $150 \mathrm{~cm}^{3}$ water during cystometry, using a fill rate of $30-100 \mathrm{~cm}^{3} / \mathrm{min}$.

(3) Duration of symptoms less than 9 months.

(4) Absence of nocturia.

(5) Symptoms relieved by antimicrobials, urinary antiseptics, anticholinergics, or antispasmodics.

(6) A frequency of urination, while awake of less than eight times per day.

(7) A diagnosis of bacterial cystitis or prostatitis within a 3-month period.

(8) Bladder or ureteral calculi.

(9) Active genital herpes.

(10) Uterine, cervical, vaginal, or urethral cancer.

(11) Urethral diverticulum.

(12) Cyclophosphamide or any type of chemical cystitis.

(13) Tuberculous cystitis.

(14) Radiation cystitis.

${ }^{1}$ These exclusion criteria traditionally also include: "The demonstration of phasic involuntary bladder contractions on cystometry using the fill rate described previously" which was not considered an exclusion in this study.
(15) Benign or malignant bladder tumors.

(16) Vaginitis.

(17) Age less than 18 years.

\section{REFERENCES}

1. Abrams P, Cardozo L, Fall M, et al. The standardisation of terminology in lower urinary tract function: Report from the standardisation sub-committee of the International Continence Society. Urology 2003;61:37-49.

2. Clemens JO, Link CL, Eggers PW, et al. Prevalence of painful bladder symptoms and effect on quality of life in black, Hispanic and white men and women. J Urol 2007;177:1390-94.

3. Fall $M$, Oberpenning F, Peeker R. Treatment of bladder pain syndrome/ interstitial cystitis 2008: Can we make evidence-based decisions? Eur Urol 2008;54:65-75.

4. Chassagne S, Bernier PA, Haab F, et al. Proposed cutoff values to define bladder outlet obstruction in women. Urology 1998;51:408-11.

5. Blaivas JG, Groutz A. Bladder outlet obstruction nomogram for women with lower urinary tract symptomatology. Neurourol Urodyn 2000;19:553-64.

6. Defreitas GA, Zimmern PE, Lemack GE, et al. Refining diagnosis of anatomic female bladder outlet obstruction: Comparison of pressure-flow study parameters in clinically obstructed women with those of normal controls. Urology 2004;64:675-9; discussion 679-81.

7. Lemack GE, Zimmern PE. Pressure flow analysis may aid in identifying women with outflow obstruction. J Urol 2000;163:1823-28.

8. Kuo HC. Urodynamic parameters for the diagnosis of bladder outlet obstruction in women. Urol Int 2004;72:46-51.

9. Nitti VW, Tu LM, Gitlin J. Diagnosing bladder outlet obstruction in women. J Urol 1999;161:1535-40.

10. Di GE, Troyo SR. Proposed urodynamic pressure-flow nomograms to diagnose female bladder outlet obstruction. Arch Ital Urol Androl 2004;76:59-65.

11. Hanno PM, Landis JR, Matthews-Cook Y, et al. The diagnosis of interstitial cystitis revisited: Lessons learned from the National Institutes of Health Interstitial Cystitis Database study. J Urol 1999;161:553-57.

12. Irwin PP, Takei M, Sugino Y. Summary of the Urodynamics Workshops on IC Kyoto. Jpn Int J Urol 2003;10:S19-S23.

13. Messing EM. The diagnosis of interstitial cystitis. Urology 1987;29:4-7.

14. Webster JR. Combined video/pressure/flow cystourethrography in female patients with voiding disturbances. Urology 1975;5:209-15.

15. Peters KM, Carrico DJ, Kalinowski SE, et al. Prevalence of pelvic floor dysfunction in patients with interstitial cystitis. Urology 2007:70:16-18.

16. Dmochowski RR. Bladder outlet obstruction: Etiology and evaluation. Rev Urol 2005;7:S3-S13.

17. Carr LK, Webster GD. Bladder outlet obstruction in women. Urol Clin North Am 1996;23:385-91.

18. Raz S, Smith RB. External sphincter spasticity syndrome in female patients. J Urol 1976;115:443-46.

19. Schmidt RA, Vapnek JM. Pelvic floor behavior and interstitial cystitis. Semin Urol 1991;9:154-59.

20. Barry MJ, Link CL, McNaughton-Collins MF, et al. Overlap of different urological symptom complexes in a racially and ethnically diverse, community-based population of men and women. BJU Int 2008;101:45-51.

21. Clemens JQ, Markossian TW, Meenan RT, et al. Overlap of voiding symptoms, storage symptoms and pain in men and women. J Urol 2007;178:1354-8; discussion 1358.

22. Akikwala TV, Fleischman N, Nitti VW. Comparison of diagnostic criteria for female bladder outlet obstruction. J Urol 2006;176:2093-97.

23. Lemack GE. Urodynamic assessment of bladder-outlet obstruction in women. Nat Clin Pract Urol 2006;3:38-44.

24. Kuo HC. Videourodynamic characteristics and lower urinary tract symptoms of female bladder outlet obstruction. Urology 2005;66:1005-09.

25. Blaivas J. Editorial comment. J Urol 2000;163:1827-27.

26. Goldman HB, Zimmern PE. The treatment of female bladder outlet obstruction. BJU Int 2006;98:359-66.

27. Chang SJ, Chiang IN, Yu HJ. The effectiveness of tamsulosin in treating women with voiding difficulty. Int J Urol 2008;15:981-5. 